is "implausible within the current petrified patent system and commercial infrastructure," and then adds that this "doesn't have to stop the dream" or "stop the discussion." I would counter that the dream of better diagnostics and therapies is being, and has been, realized by 30 years of biotech and protection thereof by an invigorated patent system in the United States (and elsewhere). Changing that now, particularly if based on the wooly-headed arguments (really, sentiments) in the editorial, is the fastest and surest way that those hopes and dreams will be dashed.

\section{COMPETING FINANCIAL INTERESTS}

The author declares no competing financial interests.

\section{Kevin E Noonan}

McDonnell Boehnen Hulbert \& Berghoff LLP, Chicago, Illinois, USA.

e-mail:noonan@mbhb.com

1. Anonymous. Nat. Biotechnol. 28, 381 (2010).

\section{Nature Biotechnology replies:}

We were not making the case that gene patenting itself was a problem, although it is clear that some DNA patents with overly broad claims are cause for concern. We disagree with the contention that "there is no evidence that Myriad Genetics...or any other gene patent holder has inhibited basic biological research by threatening patent infringement litigation.” There are cases where exclusive licensing practices (a particular problem for methods patents) or aggressive license enforcement has stymied research, as is detailed elsewhere in this issue ${ }^{1}$. The problems also reach beyond basic research: a survey of 132 clinical laboratory heads in the United States found that $53 \%$ had "decided not to develop or perform a test/service for clinical or research purposes because of a patent"2. Indeed, one of the plaintiffs in the Association for Molecular Pathology v. US Patent and Trademark Office case is a patient who would like to have their $B R C A 1$ test from Myriad independently verified by another laboratory, but cannot because of Myriad's aggressive stance that prevents other laboratories performing the test. It might be good business for Myriad, but is it reasonable to enforce intellectual property in such a manner that it is so difficult for a patient to confirm a DNA test in an independent laboratory?

The claim that new technology takes the place of 'obsolescent' technology because "patents expire" is also moot in relation to
DNA patents. A point we were trying to make in the editorial is that the fields of molecular diagnostics and sequencing are moving so quickly that they are becoming obsolete along much shorter timelines than patent terms of 20 years. Although it was not trivial to sequence a human gene 20 years ago, it is certainly becoming routine today.

1. Carbone, J. et al. Nat. Biotechnol. 28, 784-791 (2010)

2. Cho, M.K. et al. J. Mol. Diagnostics 5, 3-6 (2003).

\title{
Genetic stability in two commercialized transgenic lines (MON810)
}

\section{To the Editor:}

A letter of correspondence by Dany Morisset and his colleagues ${ }^{1}$ in the August 2009 issue cites two recent publications 2,3 $^{2}$ in which "two commercial seed varieties of the MON810 maize genetically modified event (ARISTIS BT and CGS4540) present genetic variation thus hampering the detection by several methods for MON810 (Monsanto, St. Louis)." As representatives of Monsanto Europe (Brussels), Syngenta Crop Protection (Basel) and Limagrain Services Holding (Chappes, France), we would like to correct the scientific record concerning the claimed "variation" of the transgenic insertion in these transgenic hybrids.

Upon request for further information, Margarita Aguilera and her colleagues at the European Commission, Directorate General Joint Research Center (JRC) in Ispra, Italy, informed us that the seeds tested were among 26 MON810 varieties provided by the Spanish Instituto Nacional de Investigación y Technología Agraria y Alimentaria (INIA; Madrid). The Spanish agency did not provide the JRC with details of the respective batch numbers for each variety.

Our investigation has revealed that the two deviating results were not in fact related to variation of the transgenic insertion, as reported by Aguilera et al. ${ }^{2,3}$. Instead, our conclusions are that the two varieties (reported as entry 2 and entry 5) were not MON810 maize hybrids at all.

Variety CGS4540 (entry 5) is a Bt176 maize hybrid and we do not understand why the seed was provided by INIA as MON810. Entry 2, which was designated as Aristis
$\mathrm{Bt}$, is most likely Aristis, the conventional counterpart of Aristis Bt (MON810). When we requested INIA to send a sample of Aristis Bt to its official Spanish laboratory CSIC (Consejo Superior de Investigaciones Científicas) for testing, the results were positive for MON810, as expected.

Aguilera and her colleagues were not able to provide a correct chain of custody for the samples used in their analyses, which would have allowed resolution of the origin of these deviating results.

The seed industry has invested significantly to provide quality products to the market place, which includes selling compliant and stable products. Traits are tested for presence and stability for many generations before release to the market place. We are therefore convinced that there is no scientific evidence of instability in MON810 hybrids.

\section{COMPETING FINANCIAL INTERESTS}

The authors declare competing financial interests: details accompany the full-text HTML version of the paper at http://www.nature.com/naturebiotechnology/.

\section{Sofia Ben Tahar ${ }^{1}$, Isabelle Salva \&} Ivo O Brants ${ }^{3}$

${ }^{1}$ Limagrain Services Holding, Quality Assurance, Chappes, France. ${ }^{2}$ Syngenta Crop Protection AG, Regulatory Affairs, Basel, Switzerland. ${ }^{3}$ Monsanto Europe SA, Scientific Affairs, Brussels, Belgium. e-mail:ivo.o.brants@monsanto.com

1. Morisset, D. et al. Nat. Biotechnol. 27, 700-701 (2009).

2. Aguilera, M. et al. Food Anal. Methods 1, 252-258 (2008).

3. Aguilera, M. et al. Food Anal. Methods 2, 73-79 (2009). 